\title{
"I Tried to Get Help About my Addiction but he Just gave me Tablets:"Male Aboriginal Drug and Alcohol Rehabilitation Clients' Experiences and Preferences Speaking about Substance use in Primary Care
}

Sara Farnbach ( $\nabla$ s.farnbach@unsw.edu.au )

University of New South Wales - Kensington Campus: University of New South Wales

https://orcid.org/0000-0002-7013-1079

Jamie Fernando

Access Health Care

Joe Coyte

The Glen Centre

Matthew Simms

South Coast Medical Service Aboriginal Corporation

Maree Hackett

The George Institute for Global Health

\section{Research}

Keywords: Substance-related disorders, primary health care, Health Services Accessibility, Oceanic Ancestry Group, Australia, Aboriginal

Posted Date: September 27th, 2021

DOI: https://doi.org/10.21203/rs.3.rs-929770/v1

License: (c) (1) This work is licensed under a Creative Commons Attribution 4.0 International License. Read Full License 


\section{Abstract}

\section{Background}

Primary healthcare $(\mathrm{PHC})$ services are crucial in supporting people with substance use problems. The aims of this study were to explore Aboriginal and Torres Strait Islander (hereafter Aboriginal) males in treatment for substance use problems experiences about speaking about their substance use with PHC staff, and their preferences for accessing PHC about their substance use.

\section{Methods}

Semi-structured interviews with residential drug and alcohol rehabilitation treatment service clients. Thematic analysis was used to develop themes inductively and deductively. Two interviews were independently double coded by an Aboriginal researcher and the project was supported by an Aboriginal Advisory Group.

\section{Results}

Twenty male adults who self-identified as Aboriginal participated (mean age 27 years). Half reported visiting $\mathrm{PHC}$ and talking about their substance use before their residential service stay. Two major themes developed: (1) asking for help for substance use or mental health problems linked with substance use, (2) ways to improve access to PHC about substance use. Although some males were offered treatment, some were not, and others had concerns about the treatments offered.

\section{Conclusion}

This research highlights opportunities to improve access and to better support Aboriginal males with substance use problems in PHC. Focus on culturally appropriate PHC and providing staff with training around substance use and treatment options may improve access. It is important to foster culturally appropriate services, develop PHC staff knowledge around substance use, focus on therapeutic relationships and have a range of treatment options available that can be tailored to individual circumstances.

\section{Background}

Aboriginal and Torres Strait Islander and Torres Strait Islander (hereafter referred to as Aboriginal) communities thrived before colonisation. ${ }^{1}$ Social systems, roles, social order and individual and collective wellbeing were maintained via intricate kinship, spiritual and farming systems. ${ }^{1}$ Colonisation disrupted these traditional practices. ${ }^{1,2}$ As a result of the ongoing impacts of colonisation ${ }^{3,4}$ and associated intergenerational trauma ${ }^{5,6}$, some Aboriginal communities today experience disproportionate harm from substance use (using too much alcohol or other drugs), leading to an overrepresentation of Aboriginal people attending substance use treatment services. ${ }^{7}$ Although overall there appears to be a reduction in 
the proportion of Aboriginal people who smoke and consume alcohol above the recommended amounts (according to the latest national data collected via one-week retrospective self-reported diary) ${ }^{7}$, substance use remains a national problem, accounting for approximately $6.7 \%$ of the total burden of disease and injury in the general population. ${ }^{8}$ It causes social and individual harm including family breakdown, violence, loss of income and imprisonment. ${ }^{2}$ There are particular concerns about Aboriginal males, with $37 \%$ of Aboriginal males reporting ever using illicit substance, compared to $21 \%$ of Aboriginal women. ${ }^{7}$

Substance use dependence can be a chronic and relapsing condition 9,10 , often requiring ongoing or repeated treatment to achieve sustained abstinence and maintain functioning. ${ }^{11}$ As well as paramedics and Emergency Department staff, primary healthcare (PHC) staff are often the first point of contact Aboriginal males have with the healthcare system. Initiatives such as behavioural counselling ${ }^{12}$, brief intervention, withdrawal management and cultural therapies ${ }^{13}$, can be delivered in $\mathrm{PHC}$ and for some people, a PHC-based brief intervention may be sufficient to reduce their substance use. ${ }^{14,15}$ For others who are highly dependent on substances and require more intensive treatments, PHC staff can initiate and coordinate access to treatments such as withdrawal management, psychological interventions and residential rehabilitation programs. ${ }^{11,16}$

For PHC staff to effectively intervene for those with problematic substance use, their services must be accessible ${ }^{17}$, and staff need to be well-equipped to facilitate discussions about substance use. ${ }^{18}$ Limited staff time ${ }^{19}$, multiple clinical demands ${ }^{18}$ and limited knowledge around substance use ${ }^{18}$, may hinder the extent to which substance use is discussed and managed in PHC. Stigma and negative attitudes held by PHC staff may also influence how likely they are to initiate discussions about substance use, or to offer screening or treatment options if concerns are raised by a patient. For instance, some staff may blame individuals, believe that a substance use disorder is a sign of weakness or a choice, or lack confidence that someone with a substance use disorder can be successfully treated. ${ }^{20}$ Systemic barriers also exist, with many PHC services not funded specifically to provide substance use treatments.

There may be further barriers for Aboriginal people when accessing PHC, including long distances to travel to services, limited culturally-acceptable options or experiences of racism or discrimination making them unlikely to return for appointments. ${ }^{21}$ Some Aboriginal people may prefer accessing mainstream services for substance related issues because of the anonymity ${ }^{22}$, while others can find mainstream services unacceptable or inappropriate ${ }^{23,24}$ and prefer to prioritise culturally appropriate treatments. ${ }^{22,}$ 25-27 Self-stigma is defined as an individual becoming aware of public stigma, agreeing with those stereotypes and internalising and applying them to themselves. ${ }^{28}$ When self-stigma occurs, it may reduce an individual's sense of self-respect and self-esteem, potentially reducing the likelihood of them seeking help for substance use, and their chances of achieving recovery. ${ }^{28}$ Self-stigma may be a particularly pertinent barrier for Aboriginal males accessing support for substance use, many of whom have lost welldefined meaningful roles within their communities and families as a consequence of colonisation, 
dispossession and dislocation. ${ }^{29}$ The extent to which Aboriginal males who use substances access PHC and discuss their substance use is unknown.

This study explores the needs, experiences and preferences of Aboriginal males when accessing PHC for their substance use, before they attended residential rehabilitation (defined as community-based drug and alcohol treatment centres or residential rehabilitation services). This information will be crucial in assisting PHC staff to address substance use among Aboriginal males and for informing policies around strategies to reduce the harms from substance use. In this paper, the term Aboriginal Medical Service (AMS) is used when clients report using an AMS. If clients report having a relationship with a specific General Practitioner (GP) rather than staff at either a PHC/AMS, the term GP is used.

\section{Setting}

The Glen Centre is a community controlled residential drug and alcohol treatment centre on the Central Coast of New South Wales, Australia, approximately 100 kilometres north of Sydney. The Glen Centre provides treatment to males only (at the time of this research) and is part of the Aboriginal Drug and Alcohol Residential Rehabilitation Network (ADARRN) network of Aboriginal residential rehabilitation services in NSW. The Glen Centre's rehabilitation treatment program runs for 12 weeks and involves group counselling, one to one counselling, self-help groups and work programs for up to 34 clients while they stay at the service. After completing the program, clients can apply for and stay on-site in a transition program which enables them to attend training and find and start employment or be discharged to a location of their choice.

\section{Methods}

\section{Participants}

Current male Aboriginal residential clients at The Glen Centre (residential rehabilitation service) aged 18 years or older.

\section{Aim}

To understand:

1. Experiences speaking about their substance use with PHC service staff, including if care was offered as a result of these conversations; and

2. Preferences for accessing PHC for help for their substance use, before being admitted into residential rehabilitation.

\section{Aboriginal leadership and reflexivity}

This research was conceived after one author (Aboriginal GP working in a residential rehabilitation service) noted that Aboriginal males who used substances rarely visited the PHC services where he has 
worked for help with their substance use. He questioned if Aboriginal males were presenting at PHC for help with drug and alcohol problems and whether they had preferences for how PHC access could be enhanced. This research was jointly designed and conducted by Aboriginal authors (JF and MS), Aboriginal staff at The Glen and non-Aboriginal researchers. The Aboriginal authors completed all contacts with clients, contributed to data analysis and the development of the manuscript. An Aboriginal Advisory Group was convened and included staff and representatives from the residential service to oversee the research project (e.g. to guide the recruitment strategy) and also met twice during the research to review the major themes as they developed. The active roles of the Aboriginal researchers in this research meant that they had an understanding of Aboriginal ways of knowing, being and doing and had a deep understanding of the social world in which participants were from. The Aboriginal researchers and the Aboriginal Advisory Group shaped the research topic, approach to data collection, data collection itself and is in keeping with the philosophical origins of this project (idea generation, topic selection, data collection, analysis, interpretation, and reporting).

MS is an Aboriginal drug and alcohol counsellor who completed training in qualitative data collection and analysis and research processes (informed consent, study protocol) with SF. JF is an Aboriginal GP who has completed training in qualitative data collection during his Master's in Public Health. JF worked as a GP and in other roles at The Glen from 2015 to 2019. At the time of the research, JF worked as a GP in rural NSW. SF and MLH are non-Aboriginal researchers with experience working with Aboriginal communities and the Aboriginal co-authors on previous research projects. JC is Executive Director of The Glen Centre.

\section{Approach}

A qualitative study using semi-structured interviews. Data were inductively and deductively analysed using thematic approach. ${ }^{30}$ Thematic analysis ${ }^{30}$ was chosen as it allows for a data set to be explored to identify shared meanings and experiences, therefore fits with the study goals of exploring the lived experiences of Aboriginal male clients about attending PHC.

\section{Sampling strategy}

Semi-structured interviews were completed on site with clients at The Glen between July 2017 and December 2018. In line with a thematic approach ${ }^{30}$, participants who were male adults and who selfidentified as Aboriginal were purposively identified for participation in this study. During recruitment periods, a male Aboriginal drug and alcohol counsellor who had existing relationships with clients (MS or another counsellor) reviewed the current client list to identify those who appeared to meet the eligibility criteria. The counsellor then introduced the potential participant to the study and invited them to take part. If willing, eligibility was confirmed with the client and a time was arranged to complete informed consent and the research interview. Participants were reimbursed for their time with a $\$ 25$ food voucher from a local supermarket.

\section{Data collection techniques}


Interviews were conducted using an interview guide (available on request) which included questions related to the aims. The interview guide included four broad categories: demographic information; recent experiences seeing a GP; perceived barriers to seeing a GP; and preferences for accessing a GP after leaving The Glen Centre. The guide was pilot tested by MS and SF (using the guide SF asked MS the study questions, who provided feedback which was incorporated into the final version). The male Aboriginal drug and alcohol counsellor who contacted potential participants initially completed social yarning ${ }^{31}$ and then introduced them to the research topic, purpose and process. If agreeable, they then arranged a suitable time for participants to complete informed consent and 'yarning style ${ }^{31}$ interviews, either with one interviewer or both Aboriginal interviewers present (MS, JF). When available, two interviewers completed interviews to facilitate participant comfort. This process also exposed both interviewers to the data as they were collected, which assisted with analysis and developing the themes. Interviews were digitally recorded and transcribed verbatim. NVivo 10 for Windows software ${ }^{32}$ was used to manage data.

\section{Analysis}

Following a thematic analysis approach, analysis was focused on understanding the common experiences of Aboriginal male clients. Therefore, close involvement of Aboriginal researchers was crucial to ensure cultural perspectives were central to analysis. Coding involved reading each manuscript several times. ${ }^{30}$ The purpose of the initial readings was for the researchers to become familiar with the data and to identify the interesting and significant information in each transcript. ${ }^{30}$ Subsequent readings were to inductively identify initial codes. ${ }^{30}$ Transcripts were coded by SF and two transcripts were independently coded by a second coder (JF). MS, JF and SF discussed the research progress (the developing themes and their meanings and updates to the interview guide) twice during data collection and SF took notes during these conversations. The initial codes were then developed around the aims of the research. The main themes that were commonly reported were identified. The Aboriginal Advisory Group (comprising staff and representatives from the residential service) met twice to review and discuss the main themes (after stage one and at the end of the data collection). Discussions among data coders, authors and the Advisory Group were recorded using the memos function in NVivo 10 for Windows software. ${ }^{32}$ Themes were then revised using the information recorded in the memos to ensure these discussions were reflected in the themes. Consensus around the final themes was reached among the authors and Advisory Group. This process placed Aboriginal experts' opinions as central to analysis ${ }^{2}$ and facilitated an in-depth understanding of the meaning of the data. After 10 interviews were completed (stage 1), the interview guide was updated based on analysis and these discussions and a 10 further interviews were completed. Data saturation was indicated with no new themes identified from the last three interviews (interviews 18-20).

\section{Ethics}

This research was approved by the Aboriginal Health and Medical Research Council (1260/17) and the Board at The Glen. This research was conceived, designed and conducted in line with the principles set 
out in the Ethical conduct in research with Aboriginal and Torres Strait Islander Peoples and communities: Guidelines for researchers and stakeholders developed by the National Health and Medical Research Council. ${ }^{33}$ This research is reported following the Consolidated criteria for reporting qualitative research checklist. $^{34}$

\section{Results}

Interviews were conducted with 20 males (Table 1), typically taking 12-20 minutes, resulting in approximately 245 minutes of recorded interview data. All males who were invited, participated in the research. All participants were Aboriginal. The average age was 27 years. Most males were from rural, remote or regional NSW, and this was their first or second stay at The Glen. The two major themes included: 1) Asking for help for substance use or mental health problems linked with substance use, and 2) Ways to encourage access to PHC for substance use. Sections where results are based on a subgroup of 10 participants are identified in the results ( 10 participants reported having recently seen a GP). All remaining sections include results for all 20 participants. 
Table 1

Participant demographics for Aboriginal residential drug and alcohol clients who completed interviews

\begin{tabular}{|c|c|}
\hline Participant characteristics & $N=20$ \\
\hline \multicolumn{2}{|l|}{ Ethnicity } \\
\hline Aboriginal & 20 \\
\hline Torres Strait Islander/other & 0 \\
\hline \multicolumn{2}{|l|}{ Age (mean, years) 27 years } \\
\hline \multicolumn{2}{|l|}{19 to 39 years } \\
\hline \multicolumn{2}{|l|}{ Usual residence* } \\
\hline Rural, remote or regional & 15 \\
\hline Sydney/Newcastle metropolitan & 5 \\
\hline \multicolumn{2}{|c|}{ Full or part time paid work (in the last 12 months) } \\
\hline Yes & 12 \\
\hline No & 8 \\
\hline \multicolumn{2}{|c|}{ Previous number of stays at the service (excluding current stay) } \\
\hline 0 & 9 \\
\hline 1 & 6 \\
\hline 2 & 1 \\
\hline 3 or more & 1 \\
\hline Not reported & 1 \\
\hline \multicolumn{2}{|l|}{ Main drug of choice } \\
\hline Ice/methamphetamine & 11 \\
\hline Cannabis & 2 \\
\hline Alcohol & 2 \\
\hline Other & 3 \\
\hline Not reported & 2 \\
\hline
\end{tabular}

Asking for help for substance use or mental health problems linked with substance use 
Ten participants reported that before their current stay at The Glen, they had spoken with a staff member at a PHC service about their substance use or mental health concerns (this section includes data from these 10 participants). Five of these participants perceived that their substance use was linked with mental health problems, such as anxiety, sleep problems, hearing voices, anger management or depression, and spoke of these concepts together:

So I went down there [to the PHC service] and said to them "who's the doctor? I need to see them about my drug use and a bit of depression and that..."

25 years, not in full/part time paid work before stay, justice referred, \#3

These clients reported speaking to GPs, Aboriginal Health Workers or receptionists when they were booking an appointment about their substance use or mental health problems.

Approximately half of these clients who spoke to a GP about their substance use reported that they had an established relationship with the GP, which generated trust. Clients initiated these conversations when they perceived that their substance use was causing them serious problems such as experiencing paranoia, extreme anger or they were at crisis point:

Well last time I went there, I was pretty high on ice. I told him [GP] I was hearing things and I was that paranoid I got four people following me around [describing the effects of ice].

28 years, not in full/part time paid work before stay, self-referred \#1

One participant reported telling reception staff at an AMS that he needed to see somebody about his substance use and mental health, and he was told he would have to wait for the next appointment in two hours, which he was unable to do in his current state. None described being screened for substance use by PHC staff, although the occurrence of screening was not explicitly explored during interviews.

\section{Conversations that resulted in treatment}

Some clients reported that these conversations resulted in them receiving the treatment which they sought (e.g. the clients had a Mental Health Care Plan established or were referred to a substance use treatment service) and that this was a positive outcome.

\section{Conversations that did not result in treatment}

Conversely, there were many other clients who despite wanting to be referred for treatment, were not referred. One participant, after explicitly asking for help because he was unable to stop using cocaine, was told by the GP that he didn't need treatment:

I said, mate, "I don't like this life, I don't like who I am", I'm crying aloud, and he goes, "morally you're halfway there. I don't think you need rehab ... you'll be right, just tough it out". 


\section{Problems with being prescribed medications}

When prescribed medication (e.g. to reduce anxiety or assist with sleep), many clients were reluctant to take it because they didn't feel it was the type of treatment they needed:

Yeah, I already spoke to him [GP] about that sort of stuff [substance use]. I tried to get help off him ... about my addiction and everything, but he just gave me tablets.

20 years, in full/part time paid work before stay, family/friend referred, \#8

Others were reluctant because they had previously experienced problematic side effects from medication or they thought that a more detailed assessment was needed to fully understand their problem and a prescription alone did not address their problem:

The first AMS I went to they were just asking about my sleep. And they tried to get me on tablets, which I told them I didn't want to [sic]. I went there for depression as well. And I didn't want to swap a drug for a drug.

25 years, not in full/part time paid work before stay, justice referred, \#3

\section{Unable to tell the GP the whole story}

Four clients reported that they were unable to tell the GP the whole story about their substance use. Reasons provided for not disclosing the extent of their substance use included concerns that they would receive bad news about their health, that they would be judged, due to stigma associated with substance use or that their children might be taken away as a result of these discussions:

A long time ago, prior to me coming here [to The Glen] the first time I opened up to a couple of doctors 'cause I was trying to get help, I was just so lost. And I would go into the doctors... it's actually funny 'cause I went into the doctor at [country town] and he give me [expletive] anxiety tablets or something. And he's going, "no you're right". But in saying that too, I didn't explain it 'cause I was scared to tell him I had a drug problem. I was thinking, "what if these [expletive] call DOCs [Department of Child Safety]?" I don't use around the kids.

34 years, in full/part time paid work before stay, self-referred, \#15

This meant they were not referred for treatment because the GP did not realise the extent and urgency of the clients' concerns. In contrast, one participant reported that because their GP knew them and their family, he chose not to speak about his substance use because he was concerned that his family may find out.

\section{Unable to access PHC because of substance use (analysis includes data from all participants)}


It was common for participants to report that their substance use caused their lives to be chaotic or unmanageable, and as their substance use became the priority, they stopped visiting PHC:

In the drug world, I didn't really worry about myself. So I knew what [appointments] I had [booked] but I didn't keep up with them, I just cancelled them.

32 years, in full/part time paid work before stay, medical officer and self-referred, \#12

But the last couple of years I haven't been seeing him [the GP]. I've just been on drugs and that, just didn't care about my life. [I] didn't care about my health.

28 years, not in full/part time paid work before stay, self-referred, \#1

\section{Ways to improve access to PHC about substance use (analysis includes data from all participants)}

For many clients, fostering an environment that was supportive of their needs, by visiting their regular GP, Aboriginal staff member or having a support person (family member or friend) to attend appointments with them, may increase their use of PHC. The participants also discussed improved communication between the PHC service and themselves, compensation for their time (financial or gift) and linking PHC with cultural activities as potential activities that could assist with access to PHC.

\section{Access to Aboriginal staff and the same staff member}

Four clients indicated that having access to a staff member who was also Aboriginal would be useful because they could assist with communication between themselves and PHC staff and help clients to understand health information. In addition, three reported that an Aboriginal staff member would understand their situation without judgement, which was important because some had felt judged by non-Aboriginal staff at mainstream health services:

Cause they're [non-Aboriginal staff] just not on the same level. They sit there and they like they just don't understand, they don't realise the causes of things, the reasons why you do things. They just look at what you are now and who you are now and the choices you make now, let alone [understanding] what led up to all of that.

25 years, not in full/part time paid work before stay, family/friend referred, \#11

Seven reported that they would prefer to visit the same GP on an ongoing basis because some parts of their pasts were difficult to discuss, and they didn't want to repeat their story to a new GP at each appointment:

I've had mental health issues, drug issues, alcohol issues, and some of these things are hard to talk about. And sometimes you feel like you've just got to pour your heart and soul out to a stranger. That's not the easiest thing to do.

28 years, in full/part time paid work before stay, referred through the justice system, \#9 


\section{Clients' preferences for AMS or mainstream service, depends on circumstance}

When comparing AMSs with mainstream services, four clients reported that AMSs had a more peoplefriendly and culturally appropriate approach, meaning staff had more time to spend with clients to understand their needs than at mainstream services and that this was of benefit to them. One participant reported that AMS staff were less judgemental of his circumstances than mainstream PHC staff. Conversely, three clients identified some benefits of mainstream PHC services including that they often have more appointments available, which was important when they needed to be seen urgently.

\section{Clients' seeking cultural 'support groups' or men's groups after leaving the residential service}

Three clients reported that they knew that some AMSs were linked with support groups or men's groups that had a focus on culture, such as cultural dancing or painting. For these clients, cultural programs provided opportunities for them to link their treatment with their cultural connections, and this was an important part of their recovery. Although many clients were aware that these groups existed, none reported being part of a group before they came to The Glen, and were unaware how to join such a group. Ten clients were interested in joining a group after they leave The Glen:

I hope I can find some of my mob that's doing an activity or something. I've always wanted to go through the passage of rites, like from child to man. I haven't been through that yet so in my mob's eyes I'm still a child.

\section{2 years, not in full/part time work before stay, referral not reported, \#13}

\section{Having a support person (family member or friend)}

Receiving support from a family member or friend was frequently reported by clients to be important because it prompted them into positive action around their health. Most clients were able to identify at least one family member or friend who was their support person.

\section{Improving communications between clients and PHC services}

Clearer communication between themselves and the PHC service was important to encourage clients to make initial visits and on an ongoing basis. Three clients suggested that appointment reminders sent via text-message may be a helpful prompt for them to attend appointments. Others reported that having an initial appointment with a new GP in their homes (as a home visit) would help them to trust the GP and make them more likely to attend subsequent appointments. 


\section{Compensation for clients' time}

Two clients reported that some AMSs provide clients with a jersey or a voucher after completing health checks to compensate for their time. For these clients, this compensation motivated them to attend appointments or alleviated financial stress as it helped them to prioritise their own health over other life issues:

We might have a doctor's appointment but have no money for that day and we put other stupid priorities instead of going to the health [service] like trying to get loans, trying to survive. They [community members] want to go there 'cause they get the voucher and even though it's bad 'cause it's earning money through incentives, they don't have to worry about the rest of their day, it makes it open for them to go to the doctor's appointment to get health checks.

25 years, not in full/part time paid work before stay, family/friend referred, \#11

\section{Discussion}

To our knowledge, this is the first research exploring the experiences of Aboriginal males speaking about their substance use with staff at PHC services. Although it is encouraging that half the males who took part had sought help from PHC at some stage before entering residential rehabilitation, suggesting that they were motivated to reduce or stop their substance use, it is concerning that many of these males did not receive treatment or had concerns about the type of treatment they were offered. Many males made suggestions about ways that access to PHC for substance use could be improved.

Although some participants were offered treatment after conversations about their substance use with PHC staff, many were not, and some were told they did not need treatment, despite the participants expecting or asking for it. Staff-related factors such as heavy workloads ${ }^{18}$, limited time ${ }^{19}$ and skills ${ }^{18}$, or stigma, values and negative beliefs held by staff around the likely success of treatment for substance use problems may contribute to the extent to which males report their substance use $\mathrm{s}^{35}$ and are offered treatment. ${ }^{20}$ By providing ongoing education opportunities to PHC staff around the substance use problems and management options, $\mathrm{PHC}$ access may be improved by increasing staff knowledge, skills and awareness and reducing stigma and negative beliefs. ${ }^{35}$ Although there is limited research around effective PHC-based strategies to reduce substance related harms among Aboriginal populations ${ }^{13,36}$, there is growing international evidence around the role of culturally acceptable PHC based substance use programs. Brief interventions ${ }^{37}$, screening ${ }^{38}$ and contingency management ${ }^{39}$ in Australia, and motivational interviewing incorporating culturally relevant treatments (e.g. talking circles and sweat lodge ceremonies ${ }^{40}$, drawing on spiritually and family/clan relationships as motivation and delivered by counsellors fluent in the native language ${ }^{41}$, in America, all have promise. Given that some Aboriginal people prefer to prioritise culturally appropriate treatments $22,25-27$, this focus on culturally relevant 
programs is warranted and continued efforts in this area may enhance PHC services' role in identifying and supporting Aboriginal males who have substance use problems.

As has been found previously with Australian Aboriginal women ${ }^{42}$, some males did not disclose the extent of their substance use to GPs for a variety of reasons. These findings further highlight the importance of providing PHC staff with training and information around substance use problems and available treatment options. PHC needs to be a safe place where people develop trust with PHC staff so they feel comfortable to speak openly about their concerns, without judgement or welfare repercussions, and can expect to receive or be referred for culturally appropriate treatment when it is requested.

Cultural support and culturally-appropriate approaches are important elements of residential drug and alcohol treatment services for Aboriginal clients. ${ }^{25-27}$ Participants in this study described culturallyappropriate services as those with staff who have time to understand their needs, with Aboriginal staff and where they did not feel judged. Problematic substance use arises from a range of complex social and historical determinants, ${ }^{43}$ including trauma ${ }^{2}$, and these findings indicate that clinicians who understand these causes and with whom males do not feel judged by is important when discussing and treating substance use problems. Recognising this need, the peak organisation for Aboriginal residential rehabilitation services in NSW (ADARRN) has developed a model of care which incorporates evidencebased practice with embedded cultural values. ${ }^{27}$ The model of care includes six core components and activities to operationalise each core component that can be standardised in any Aboriginal residential rehabilitation service. ${ }^{27}$ One of the components is cultural healing, meaning that each service can tailor cultural activities according to their context and circumstances. ${ }^{27}$ In the PHC setting, many AMSs ${ }^{44}$ have a culturally-informed service delivery focus in efforts to recognise historical factors and centralise culture. Access to mainstream PHC services may be improved by increased focus on culturally-appropriate approaches.

Although access to Aboriginal staff was identified as important (because they may assist with communication and were less likely to be judgemental), staffing continuity between appointments was also important because clients did not want to repeat their story at each appointment. This is understandable, given the sensitive nature of substance use problems and its links with trauma. ${ }^{2}$ Together with the diverse opinions expressed by the participants about their preference to visit a mainstream GP or AMS, these findings highlight that as well as focusing on culturally-informed services, a range of options and services should be available, treatment should be individually tailored and culturally safe and relevant activities and groups post residential rehabilitation should be encouraged.

A strength of this research is the active role of the Aboriginal researchers in conception, design, analysis and reporting of this project. Another strength is the existing relationship between participants and the interviewers which may have encouraged open and honest conversations. Although these relationships may have caused clients to report more positively their attendance at PHC, we believe this approach facilitated the research by encouraging participation as all eligible males who were asked, took part. Use of the semi-structured interview guide meant that detailed information about the experiences of 
participants was gained. The interview guide was updated based on the responses of early participants and the framework was revised as interviews were coded. This research may be limited by recall bias as it relied on participants recalling difficult events from a long time ago for some. This is a small research study including 20 males from one Aboriginal residential rehabilitation service. All were from NSW. There may be differences between the participants and those who were unable or unwilling to take part, including clients who dropped out of the program early or were not asked, which may have led to selection bias. As such these findings may not be generalisable to other contexts or other residential rehabilitation services.

This research highlights the importance of fostering a PHC environment where discussions about substance use are likely to occur. To support PHC services to provide such care, structural issues should be addressed such as making funding available to deliver care around substance use problems. Staff should be offered training build knowledge around effective strategies to support people with substance use problems, and working with Aboriginal people. Further research is needed into the impact of models such as the standardised model of care in Aboriginal residential rehabilitation services, ${ }^{27}$ in order to identify the extent to which these can improve outcomes for Aboriginal clients and if they can be extended to other settings, such as PHC. This research provides an example of a co-designed research project, which was initiated by Aboriginal staff and completed in partnership with non-Aboriginal researchers.

\section{Conclusions}

The challenges the Aboriginal males faced when speaking about their substance use with the hope of accessing treatments is concerning and highlights the need for developing PHC staff knowledge around substance use treatments, delivery of culturally-appropriate care, focusing on developing ongoing therapeutic relationships and having a range of treatment options available that can be tailored to individual circumstances. This research is encouraging as it shows that many Aboriginal males in treatment for substance use problems had sought help from PHC, demonstrating a keen interest in improving their health.

\section{Declarations}

\section{Ethics approval and consent to participate}

This research was approved by the Aboriginal Health and Medical Research Council (1260/17). Participants completed informed consent.

\section{Consent for publication}

Not Applicable. 


\section{Availability of Data and Materials}

The datasets generated and/or analysed during the current study are not publicly available due to the sensitive nature of the datasets and personal information provided by participants, but are available from the corresponding author on reasonable request.

\section{Competing interests}

The authors have no competing interests to declare.

\section{Funding}

During the completion of this work, Sara Farnbach was in receipt of a University of Sydney Faculty of Medicine Cross Cultural Public Health Research Award and a George Institute for Global Health John Chalmers Program Grant Scholarship; Maree L. Hackett was in receipt of a National Heart Foundation Future Leader Fellowship \#100034 and an NHMRC Career Development Fellowship Level 2 APP1141328.

\section{Authors contributions}

The concept for this project was suggested by JF and developed by JF, SF and MH. SF and JF led this research including protocol development, data analysis and coordinating feedback from the Advisory Group. JF and MS completed the interviews. JF, MS, CM and JC comprise the Advisory Group. SF drafted the manuscript and all authors contributed to the final manuscript.

\section{Acknowledgement}

We would like to acknowledge all the clients who participated in this study.

\section{References}

1. Pascoe B. Dark emu black seeds: Agriculture or accident? Magabala Books; 2014.

2. Working Together. Aboriginal and Torres Strait Islander Mental Health and Wellbeing Principles and Practice. Purdie N, Dudgeon P, Walker R, editors. Canberra: Department of Health and Aging; 2010.

3. Calma T, Dudgeon P, Bray A. Aboriginal and Torres Strait Islander Social and Emotional Wellbeing and Mental Health. Australian Psychologist. 2017;52(4):255-60.

4. Sherwood J. Colonisation-It's bad for your health: The context of Aboriginal health. Contemp Nurse. 2013;46(1):28-40. 
5. Testro P, Ryan K, Hillan L. Restoring our spirits - reshaping our futures creating a trauma aware, healing informed response to the impacts of institutional child sexual abuse for Aboriginal and Torres Strait Islander people. Canberra: The Healing Foundation; 2016.

6. Atkinson J. Trauma trails, recreating song lines: The transgenerational effects of trauma in Indigenous Australians. North Melbourne: Spinifex Press; 2002.

7. Australian Institute of Health Welfare. Alcohol, tobacco \& other drugs in Australia. Canberra: AlHW; 2020.

8. Australian Institute of Health and Welfare. Impact of alcohol and illicit drug use on the burden of disease and injury in Australia. 2011.

9. Ritter A, King T, Hamilton M. Drug Use in Australian Society. Melbourne: Oxford Univeristy Press; 2013.

10. Haber P, Lintzeris N, Proude E, Lopatko O. Guidelines for the treatment of alcohol problems. Canberra: Commonwealth Dept of Health and Ageing; 2009.

11. NSW Department of Health. Drug \& Alcohol Treatment Guidelines for Residential Settings. Sydney: Mental Health and Drug and Alcohol Office; 2007.

12. Jonas DE, Garbutt JC, Amick HR, Brown JM, Brownley KA, Council CL, et al. Behavioral counseling after screening for alcohol misuse in primary care: a systematic review and meta-analysis for the US Preventive Services Task Force. Ann Intern Med. 2012;157(9):645-54.

13. Purcell-Khodr GC, Lee KSK, Conigrave JH, Webster E, Conigrave KM. What can primary care services do to help First Nations people with unhealthy alcohol use? A systematic review: Australia, New Zealand, USA and Canada. Addiction Science Clinical Practice. 2020;15(1):31.

14. Lubman DI, Hides L, Yücel M, Toumbourou JW. Intervening early to reduce developmentally harmful substance use among youth populations. Med J Aust. 2007;187(S7):22-S5.

15. Clifford A, Shakeshaft A, Deans C. Training and tailored outreach support to improve alcohol screening and brief intervention in Aboriginal Community Controlled Health Services. Drug alcohol review. 2013;32(1):72-9.

16. Ritter A, Stoove M. Alcohol and other drug treatment policy in Australia. Med J Aust. 2016;204(4):138.

17. Corscadden L, Levesque J-F, Lewis V, Breton M, Sutherland K, Weenink J-W, et al. Barriers to accessing primary health care: comparing Australian experiences internationally. Aust J Prim Health. 2017;23(3):223-8.

18. Allan J. Engaging primary health care workers in drug and alcohol and mental health interventions: challenges for service delivery in rural and remote Australia. Australian Journal of Primary Health. 2010;16(4):311-8.

19. Allan J. Advanced rural skills training: The value of an addiction medicine rotation. Aus Fam Physician. 2011;40(11):927. 
20. van Boekel LC, Brouwers EP, van Weeghel J, Garretsen HF. Healthcare professionals' regard towards working with patients with substance use disorders: Comparison of primary care, general psychiatry and specialist addiction services. Drug Alcohol Depend. 2014;134:92-8.

21. Davy C, Harfield S, McArthur A, Munn Z, Brown A. Access to primary health care services for Indigenous peoples: A framework synthesis. Int J Equity Health. 2016;15(1):163.

22. Teasdale KE, Conigrave KM, Kiel KA, Freeburn B, Long G, Becker K. Improving services for prevention and treatment of substance misuse for Aboriginal communities in a Sydney Area Health Service. Drug Alcohol Rev. 2008;27(2):152-9.

23. Gray D, Stearne A, Wilson M, Doyle M. Indigenous-specific alcohol and other drug interventions: continuities, changes and areas of greatest need. National Drug Research Institute, Curtin University, Australian National Council on Drugs; 2010.

24. Brett J, Lee KSK, Gray D, Wilson S, Freeburn B, Harrison K, et al. Mind the gap: What is the difference between alcohol treatment need and access for Aboriginal and Torres Strait Islander Australians? Drug Alcohol Rev. 2016;35(4):456-60.

25. Munro A, Allan J, Shakeshaft A, Breen C. "I just feel comfortable out here, there's something about the place": staff and client perceptions of a remote Australian Aboriginal drug and alcohol rehabilitation service. Substance abuse treatment, prevention, and policy. 2017;12(1):49.

26. Chenhall D, Senior R. K. "The concepts are universal, it is the picture you paint that is different": key issues for Indigenous Australian alcohol and drug residential treatment centres. Therapeutic Communities: The International Journal of Therapeutic Communities. 2013;34(2/3):83-95.

27. James DB, Lee KSK, Patrao T, Courtney RJ, Conigrave KM, Shakeshaft A. Understanding the client characteristics of Aboriginal residential alcohol and other drug rehabilitation services in New South Wales, Australia. Addiction Science \& Clinical Practice. 2020;15(1):27.

28. Crapanzano KA, Hammarlund R, Ahmad B, Hunsinger N, Kullar R. The association between perceived stigma and substance use disorder treatment outcomes: a review. Substance abuse rehabilitation. 2019;10:1.

29. HealthBulletin Al. Review of Indigenous male health 2010 [Available from: http://healthbulletin.org.au/articles/Review-of-indigenous-male-health.

30. Braun V, Clarke V. Thematic analysis. In: Cooper H, Camic PM, Long DL, Panter AT, Rindskopf D, Sher KJ, editors. APA handbook of research methods in psychology, Vol 2: Research designs: Quantitative, qualitative, neuropsychological, and biological. APA handbooks in psychology ${ }^{\circledR}$. Washington: American Psychological Association, American Psychological Association, Washington, DC;; 2012. pp. 57-71. Chapter $x, 701$ Pages.

31. Bessarab D, Ng'andu B. Yarning about yarning as a legitimate method in Indigenous research. International Journal of Critical Indigenous Studies. 2010;3(1):37-50.

32. QSR International Pty Ltd. NVivo 10 for Windows 2013 [Accessed 01/11/2015]. Available from: http://www.qsrinternational.com/product. 
33. Commonwealth of Australia. Ethical conduct in research with Aboriginal and Torres Strait Islander Peoples and communities: Guidelines for researchers and stakeholders. Canberra; 2018.

34. Tong A, Sainsbury P, Craig J. Consolidated criteria for reporting qualitative research (COREQ): a 32item checklist for interviews and focus groups. International journal for quality in health care. 2007;19(6):349-57.

35. Ross LE, Vigod S, Wishart J, Waese M, Spence JD, Oliver J, et al. Barriers and facilitators to primary care for people with mental health and/or substance use issues: a qualitative study. BMC Family Practice. 2015;16(1):135.

36. Dzidowska M, Lee KK, Wylie C, Bailie J, Percival N, Conigrave JH, et al. A systematic review of approaches to improve practice, detection and treatment of unhealthy alcohol use in primary health care: a role for continuous quality improvement. BMC Fam Pract. 2020;21(1):1-22.

37. Conigrave K, Freeman B, Caroll T, Simpson L, Lee K, Wade V, et al. The Alcohol Awareness project: community education and brief intervention in an urban Aboriginal setting. Health Promot $\mathrm{J}$ Austr. 2012;23(3):219-25.

38. Islam MM, Oni HT, Lee KSK, Hayman N, Wilson S, Harrison K, et al. Standardised alcohol screening in primary health care services targeting Aboriginal and Torres Strait Islander peoples in Australia. Addict Sci Clin Pract. 2018;13(1):5.

39. Hirchak KA, Leickly E, Herron J, Shaw J, Skalisky J, Dirks LG, et al. Focus groups to increase the cultural acceptability of a contingency management intervention for American Indian and Alaska Native Communities. Journal of substance abuse treatment. 2018;90:57-63.

40. Woodall WG, Delaney HD, Kunitz SJ, Westerberg VS, Zhao H. A randomized trial of a DWI intervention program for first offenders: intervention outcomes and interactions with antisocial personality disorder among a primarily American-Indian sample. Alcohol Clin Exp Res. 2007;31(6):974-87.

41. Venner KL, Greenfield BL, Hagler KJ, Simmons J, Lupee D, Homer E, et al. Pilot outcome results of culturally adapted evidence-based substance use disorder treatment with a Southwest Tribe. Addictive Behaviors Reports. 2016;3:21-7.

42. Lee KK, Harrison K, Mills K, Conigrave KM. Needs of Aboriginal Australian women with comorbid mental and alcohol and other drug use disorders. Drug Alcohol Rev. 2014;33(5):473-81.

43. Wilkinson R, Marmot M, editors. Social Determinants of Health: The Solid Facts. 2nd ed. Copenhagen: World Health Organisation; 2003.

44. National Aboriginal Community Controlled Health Organisation. Definitions 2020 [Available from: https://www.naccho.org.au/about/aboriginal-health/definitions/.

\section{Supplementary Files}

This is a list of supplementary files associated with this preprint. Click to download.

- COREQChecklistltriedtogethelp.docx 